\title{
RECONHECIMENTO, VALIDAÇÃO E CERTIFICAÇÃO DE ADQUIRIDOS EXPERIENCIAIS NO ALENTEJO: RESULTADOS E IMPACTOS DO PROCESSO REALIZADO ENTRE 2000 E $2005^{1}$
}

\author{
Bravo Nico $^{2}$, Lurdes Pratas Nico ${ }^{3}$, Fátima Ferreira ${ }^{4}$, Antónia Tobias ${ }^{5}$
}

\begin{abstract}
Resumo
Na região Alentejo, e em todo o país, é conhecido o problema estrutural ao nível da qualificação escolar e profissional da população. A partir do ano 1999, com a criação da Agência Nacional de Educação e Formação de Adultos (ANEFA), começa a emergir, no território alentejano, em particular, e no país, em geral, um novo dispositivo educacional que visava promover o reconhecimento, validação e certificação das competências (RVCC) e conhecimentos adquiridos ao longo da vida, à semelhança do que já, há algumas décadas, vinha a ocorrer noutros países, que não apenas europeus (Estados Unidos, Canadá, Reino Unido, França, México, Brasil, entre outros). Neste contexto, em Portugal, surgiram, em 2000, os primeiros Centros de RVCC (CRVCC) com o objectivo de reconhecer, validar e certificar as competências dos adultos, com idade igual ou superior a 18 anos, que não possuíssem a escolaridade básica, no sentido de melhorar os níveis de certificação escolar, promover a continuação de processos subsequentes de educação e formação, numa perspectiva de Aprendizagem ao Longo da Vida, e aumentar as suas oportunidades de empregabilidade e de mobilidade profissional e social. Na presente comunicação, apresentam-se alguns dos resultados do estudo dos impactos, pessoais, profissionais e sociais, do processo de Reconhecimento, Validação e Certificação de Competências (RVCC) no universo de indivíduos que, em toda a região Alentejo, no período 2000-2005, nele tendo participado, viram certificadas as suas competências e, em consequência, alterados os respectivos níveis de escolaridade. A investigação que suporta a comunicação e que se encontra em curso, de natureza descritiva, assumiu uma base metodológica quantitativa, com o recurso à aplicação de questionário a todo o universo. A análise em curso assumiu uma dimensão geográfica e institucional, no sentido de serem possíveis leituras territorializadas e institucionais dos resultados, de acordo com as divisões administrativas e geográficas existentes na região Alentejo (distritos, concelhos e freguesias) e as instituições promotoras dos CRVCC existentes no período em estudo.
\end{abstract}

Palavras-Chave: Qualificação de Adultos; (RVCC) Reconhecimento, Validação e Certificação de Competências; Alentejo

\section{A criação do Sistema Nacional de Reconhecimento, Validação e Certificação de Competências.}

Para se compreender a génese do dispositivo que, em Portugal, veio permitir o reconhecimento e validação das competências adquiridas pela via da experiência, importa relembrar o trabalho desenvolvido pelo Grupo de Trabalho para o Desenvolvimento da Educação de Adultos (Despacho n. ${ }^{\circ}$ 10534/97, de 16 de Outubro) que, em 1997, deu lugar ao Grupo de Missão para o Desenvolvimento da Educação e Formação de Adultos (GMEFA, através da Resolução do Conselho de Ministros n. ${ }^{\circ} 92 / 98$, de 14 de Julho), o qual foi incumbido de desencadear o processo conducente à constituição da Agência Nacional de Educação e Formação de Adultos, em 1999.

\footnotetext{
${ }^{1}$ Comunicação decorrente do projecto de investigação "As novas Núpcias da Qualificação no Alentejo" promovido pelo Centro de Investigação em Educação e Psicologia da Universidade de Évora e financiado pela Fundação para a Ciência e a Tecnologia (ref ${ }^{a}$ PTCD CPE-CED/104072/2008/FCCOMP-01-0124FEDER-009154)

${ }^{2}$ Centro de Investigação em Educação e Psicologia da Universidade de Évora/Investigador-Responsável

${ }^{3}$ Direcção-Geral dos Estabelecimentos Escolares - Direcção de Serviços da Região Alentejo

${ }^{4}$ Centro de Investigação em Educação e Psicologia da Universidade de Évora

${ }^{5}$ Centro de Investigação em Educação e Psicologia da Universidade de Évora
} 
Através do Decreto-Lei n. ${ }^{\circ}$ 387/99, de 28 de Setembro, foi criada a ANEFA, como instituto público, sujeito à dupla tutela dos Ministros da Educação e do Trabalho e da Solidariedade, funcionando em regime de instalação, por um período de dois anos. Através daquele decreto, definiram-se, ainda, as suas atribuições, a sua estrutura e o seu funcionamento. Esta Agência esteve a funcionar entre 1999 e 2002.

À data da criação da ANEFA, coexistiam, na sociedade portuguesa, dois níveis de sub-certificação (Alonso et al, 2001): a sub-certificação formal (relacionada com as competências de base e decorrente do abandono precoce dos estudos ou da inexistência da oportunidade de estudar); a sub-certificação informal (com referência às competências adquiridas pela via da experiência e à inexistência de dispositivos que reconhecessem essas competências). O problema da sub-certificação escolar da população activa era, entre outras, uma preocupação evidenciada por Benavente et al (1996).

Face aos baixos níveis de qualificação da população portuguesa (sub-certificação formal e informal), foi necessário dar uma resposta de qualificação adequada à população adulta $^{6}$. Em 2000 foram, assim, criados, numa iniciativa da ANEFA, os Centros de Reconhecimento, Validação e Certificação de Competências (CRVCC), nos quais se realizaram os primeiros processos de Reconhecimento, Validação e Certificação de Competências.

O sistema nacional de RVCC concretiza-se, assim, numa rede de centros articulados entre si (Portaria n. ${ }^{\circ}$ 1082-A/2001, de 5 de Setembro). Esta rede é, desde Novembro de 2000, constituída, numa fase experimental, por 6 Centros-piloto (centros em observação) em todo o contexto nacional. Na região Alentejo, a entidade que integrou este projecto-piloto foi a ESDIME - Agência para o Desenvolvimento Local do Alentejo e Sudoeste, Lda. (com sede em Messejana).

Em Portugal, a implementação do dispositivo de RVCC desenvolveu-se em duas fases: a primeira, entre 2000-2005; a segunda, entre 2006 e 2010. Numa primeira fase, os Centros denominavam-se Centros de Reconhecimento, Validação e Certificação de Competências (CRVCC) e foram promovidos, essencialmente, por entidades privadas; numa segunda fase, e no âmbito da criação da Iniciativa Novas Oportunidades, os Centros passam a designar-se Centros Novas Oportunidades (CNO) e assistimos a um alargamento da rede à escola pública.

\section{Caracterização da rede de CRVCC e do processo de Reconhecimento, Validação e Certificação de Competências (RVCC)}

\subsection{A rede inicial de $\mathrm{CRVCC}$}

Entre 2000 e 2005, existiam em Portugal 98 CRVCC, dos quais 6 na região do Alentejo (Nico, 2009, 2011), tutelados pela ANEFA, de acordo com a cronologia que se apresenta de seguida: Esdime (Associação para o Desenvolvimento Local no Alentejo Sudoeste/Messejana 2000); Fundação Alentejo (Évora, 2001); Centro de Formação Profissional de Portalegre do IEFP (2001; Associação para o Desenvolvimento do Litoral Alentejano (Santiago do Cacém, 2003); Rota do Guadiana (Associação de Desenvolvimento Integrado/Serpa, 2004); Associação Terras Dentro (AlcáçovasViana do Alentejo/2005).

A nível nacional, entre 2000 e 2005, através de um Processo de RVCC, foram certificados 44253 adultos $^{7}$ (Nico, 2009:263). Na região Alentejo, em igual período, os seis CRVCC, já referidos, certificaram um total de 2969 adultos $^{8}$ (Nico, 2009:274).

\footnotetext{
${ }^{6} \mathrm{Em}$ 2001, 62\% dos activos tinha uma escolaridade inferior a 9 anos (INE).

${ }^{7}$ Agência Nacional para a Qualificação. SIGO, -dados provisórios actualizados a 30 de Novembro (2008).

${ }^{8}$ Direcção-Geral de Formação Vocacional, 2006.
} 


\subsection{Caracterização do processo de RVCC}

O processo de RVCC é desenvolvido tendo por base os Referenciais de Competências-Chave, conforme o nível de certificação que se pretenda obter (nível básico ou secundário) e é concretizado em 3 eixos fundamentais: o eixo do reconhecimento, o eixo da validacão e o eixo da certificacão.

(i) O eixo de reconhecimento de competências é o "processo de identificação pessoal das competências previamente adquiridas e que se consubstancia no conjunto de actividades, assentes numa lógica de balanço de competências" "9 $\mathrm{O}$ adulto é acompanhado num processo de reflexão sobre as competências que adquiriu ao longo da vida por via das experiências "quer em contextos formais de aprendizagem e trabalho, quer em contextos informais e não formais", as quais são transferíveis a outras situações (ANEFA, 2002:30). O adulto realiza várias actividades, com recurso a instrumentos disponíveis pela entidade que gere a rede e pela própria equipa pedagógica. A realização de um processo de RVCC, nomeadamente a partir do processo de Balanço de Competências, implica, por parte do adulto, a construção do Portefólio Reflexivo de Aprendizagens (inicialmente denominado de Dossier Pessoal).

(ii) $\mathrm{O}$ eixo de validação de competências é o acto através do qual os formadores validam as competências em função daquilo que está consignado nos Referenciais de Competências-Chave. Na fase inicial dos processos, o eixo de validação concretizava-se numa sessão de júri de validação constituída pelos elementos da equipa do Centro e um elemento externo (o avaliador externo), devidamente acreditado pela ANEFA. Actualmente, esta sessão ocorre, apenas, entre os elementos da equipa pedagógica.

(iii) O eixo de certificação de competências "é o processo que confirma as competências adquiridas em contextos formais, não formais e informais e que constitui o acto oficial de registo das competências "10 Este registo de competências, numa primeira fase, era efectuado na Carteira Pessoal de Competências-Chave. Esta carteira foi extinta e, em seu lugar, criouse a Caderneta Individual de Competências (Portaria n..$^{\circ}$ 475/2010, de 8 de Julho), onde se registam as competências adquiridas ou desenvolvidas pelo indivíduo ao longo da vida, referidas no Catálogo Nacional de Qualificações.

\section{A criação dos CNO}

Os CRVCC são, desde o início de 2006, sujeitos a profundas alterações de natureza legal e ao nível organizacional e de gestão, pois os seus objectivos e funções são alterados para que possam estar em conformidade com os princípios preconizados na Iniciativa Novas Oportunidades, no que à população adulta diz respeito, sob a tutela da Agência Nacional para a Qualificação, I.P., entre 2007 e 2011.

Os CRVCC passam, então, a designar-se Centros Novas Oportunidades (CNO), integram novos profissionais, o processo de RVCC é alargado ao nível secundário de educação e aumenta o número de Centros a funcionar, em todo o país (Portaria n. ${ }^{\circ}$ 370/2008, de 21 de Maio).

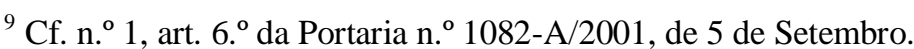

${ }^{10}$ Cf. art. $8 .^{\circ}$ da Portaria n. ${ }^{\circ} 1082-\mathrm{A} / 2001$, de 5 de Setembro.
} 
Os CNO acolhem os adultos, procedendo ao seu aconselhamento e orientação para percursos de qualificação de nível básico ou secundário e realizam os processos de RVCC escolares e profissionais.

A monitorização e avaliação dos CNO é feita através de um Sistema de Indicadores de Referência para a Qualidade dos CNO presente na Carta de Qualidade dos Centros Novas Oportunidades (Gomes \& Simões, 2007) e através do modelo de auto-avaliação $C A f$.

$\mathrm{Na}$ escola pública, e também nas instituições da sociedade civil e nas empresas, nos últimos anos, apostou-se num conjunto de medidas que visaram a melhoria da qualificação dos jovens e dos adultos portugueses. Essas medidas foram inscritas na referida Iniciativa Novas Oportunidades.

Estudos e relatórios da Comissão Europeia assinalaram os progressos que Portugal alcançou em matéria de educação e formação, o que são resultado das políticas desenhadas e concretizadas nos últimos anos. É de referir também os estudos nacionais de avaliação externa à Iniciativa Novas Oportunidades, cujos resultados já estão publicados (Carneiro, 2010), assim como os estudos regionais que avaliam os impactos dos processos de RVCC desenvolvidos entre 2001 e 2005 (ESDIME, 2007; Nico, 2009; Rico \& Libório, 2009).

A valorização da educação dos adultos através da Iniciativa Novas Oportunidades, na qual se inscrevia o dispositivo de RVCC, permitiu o acesso a uma resposta de qualificação a mais de 1 milhão e 700 mil portugueses.

Em 2010, o Sistema Nacional de RVCC era concretizado numa rede de 454 CNO disseminados por todo o país ${ }^{11}, 40$ dos quais na região Alentejo. ${ }^{12}$ Nesta região foram já certificados, através de processos de Reconhecimento, Validação e Certificação de Competências um total de 26703 adultos. $^{13}$

\section{Da extinção dos Centros Novas Oportunidades à criação dos Centros para a Qualificação e o Ensino Profissional}

Actualmente, o instituto que, a nível central, tem a missão de coordenar a rede de Centros Novas Oportunidades e o Sistema Nacional de RVCC é a Agência Nacional para a Qualificação e o Ensino Profissional (ANQEP, I.P.).

Presentemente, a rede de CNO, tal como a conhecemos, está numa fase de reorganização, quer ao nível da sua missão, quer na dimensão da rede, numa preocupação de estruturar respostas que promovam a formação profissional e aprendizagem ao longo da vida, de jovens e de adultos.

A actual rede de Centros será extinta em 31 de Março de 2013, prevendo-se a criação dos Centros para a Qualificação e o Ensino Profissional (CQEP), em substituição dos Centros Novas Oportunidades.

Podemos, assim, referir que estamos a iniciar uma $3{ }^{a}$ fase de implementação do processo de RVCC, em Portugal. À presente data, encontra-se em discussão pública, o projecto de Portaria que irá regular a criação e o funcionamento dos CQEP. ${ }^{14}$

Apesar da incerteza que existe quanto ao futuro, no que respeita à educação de adultos e, em concreto, ao dispositivo de RVCC, é indiscutível a importância de aprender continuamente ao longo da vida, o que exige a existência de estruturas e de mecanismos que possibilitem aos adultos continuar a aprender e a ver reconhecidas as suas competências, independentemente do local onde as mesmas foram adquiridas.

\footnotetext{
11 Agência Nacional para a Qualificação, I.P., 31 de Agosto de 2010.

${ }^{12}$ Assumida, neste contexto, como a zona de jurisdição da Comissão de Coordenação e Desenvolvimento Regional do Alentejo (CCDRA). Esta circunscreve 47 concelhos, distribuídos pelos distritos de Évora, Beja, Portalegre e uma parte do distrito de Setúbal (neste último, apenas os concelhos de Sines, Santiago do Cacém, Alcácer do Sal e Grândola).

${ }^{13}$ DREAlentejo, em 16.03.2012.

${ }^{14}$ http://www.anqep.gov.pt/default.aspx
} 
5. Impactos do Processo de Reconhecimento, Validação e Certificação de Competências na Região Alentejo, no período entre 2000 e 2005

\subsection{Caracterização dos indivíduos participantes no estudo}

A população do estudo é composta por 2969 indivíduos que, entre 2000 e 2005, na região Alentejo concretizaram um processo de Reconhecimento, Validação e Certificação de Competências, nos seis CRVCC, em funcionamento durante aquele período. De seguida, proceder-se-á à caracterização dos participantes no estudo.

\section{a. Origem Institucional dos inquiridos}

Do total de 2969 adultos certificados entre 2000 e 2005, 785 responderam ao inquérito por questionário, verificando-se uma taxa de retorno de $26,4 \%$. A distribuição do $\mathrm{n}^{\circ}$ de inquéritos, por CRVCC é a seguinte:

\section{Figura 1 - Número de respondentes por CRVCC}

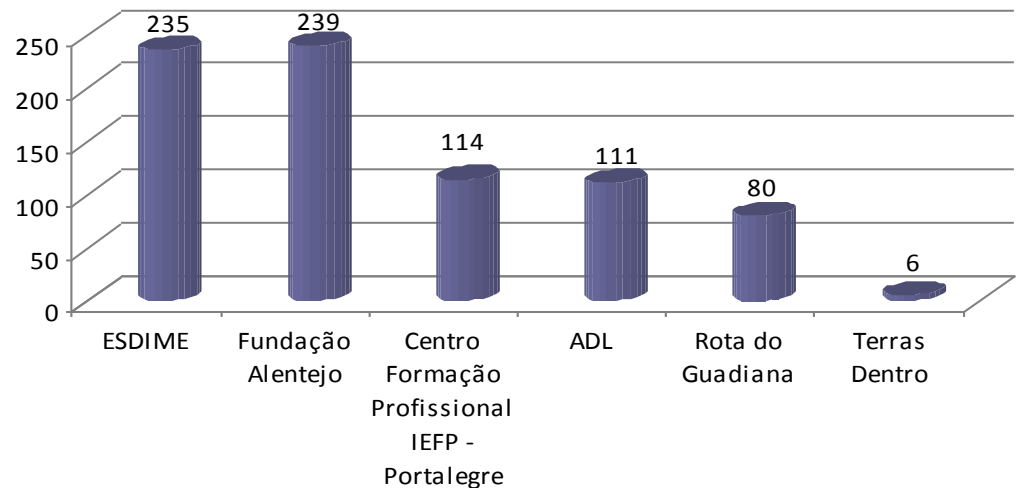

Fonte: Inquérito por Questionário das Novas Qualificações, 2011

Da leitura da figura anterior, podemos reter alguns aspectos que consideramos importantes:

- O CRVCC com o maior número de questionários respondidos foi a Fundação Alentejo, com 239 questionários válidos, que correspondem a $30,4 \%$ da amostra.

- O segundo CRVCC com maior número de questionários respondidos foi ESDIME, com 235 questionários, correspondendo a $\mathbf{2 9 , 9 \%}$ da amostra identificada.

\section{b. Género}

Como podemos verificar pela análise do Quadro 1, dos 785 adultos respondentes, mais de metade são mulheres, verificando-se uma frequência relativa de 58\%.

\section{Quadro 1: Género}

\begin{tabular}{|l|c|c|}
\hline \multicolumn{1}{|c|}{ Género } & $\begin{array}{c}\text { Frequência Absoluta } \\
\left(\mathbf{n} \mathbf{.}^{\mathbf{}}\right)\end{array}$ & $\begin{array}{c}\text { Frequência Relativa } \\
(\mathbf{\%})\end{array}$ \\
\hline Masculino & 323 & 41,1 \\
\hline Feminino & $\mathbf{4 5 5}$ & $\mathbf{5 8 , 0}$ \\
\hline Sem resposta & 7 & 0,9 \\
\hline Totais & 785 & 100 \\
\hline
\end{tabular}




\section{c. Idade}

No que respeita à idade, verifica-se um maior número de respondentes no grupo etário entre os 41 e os 50 anos, correspondendo a 36,4\% da amostra. Os grupos etários situados nos extremos (21-30 e 61-70 anos) apresentam um menor número de respostas, conforme se pode observar na Figura 2.

\section{Figura 2: Idade}

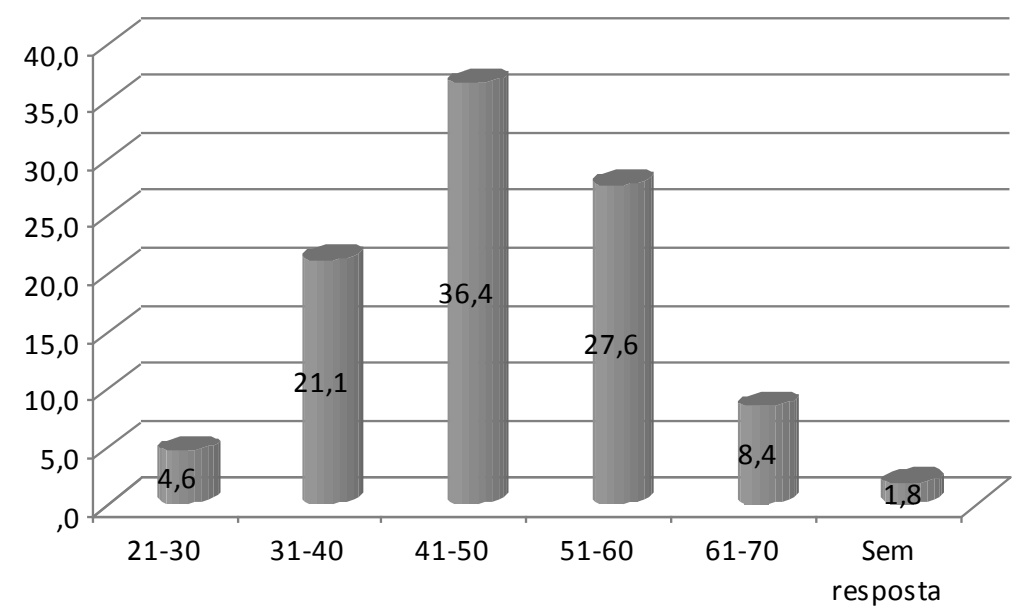

Fonte: Inquérito por Questionário das Novas Qualificações, 2011

\section{d. Situação face ao emprego no momento de início do processo de RVCC}

No que respeita à situação face ao emprego, no início do processo de RVCC, verificamos que, dos 785 adultos, estavam 644 indivíduos empregados (82\% do total) e 121 desempregados $(15,4 \%$ do total $)$.

\section{Figura 3 - Adultos certificados por situação face ao emprego}

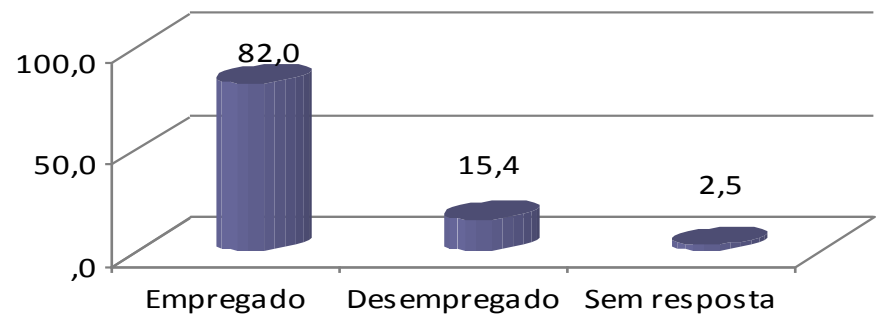

Fonte: Inquérito por Questionário das Novas Qualificações, 2011 


\subsection{O Processo de RVCC}

\section{. Formas de conhecimento}

De acordo com a Figura 4, das diversas formas de conhecimento, aquela que reuniu um maior número de escolhas foi o item "conversas informais" com amigos, familiares e conhecidos (53,4\%). O "passa palavra" parece ter assumido um papel fundamental na divulgação do trabalho dos CRVCC, em concreto do processo de RVCC, aí concretizado.

No início de funcionamento dos CRVCC, a divulgação da actividade do Centro, envolvendo os Meios de comunicação social e Internet era ainda pouco significativa, com algum relevo apenas na imprensa regional, tal como nos indicam as respostas dos inquiridos.

\section{Figura 4 - Formas de conhecimento do processo de RVCC}

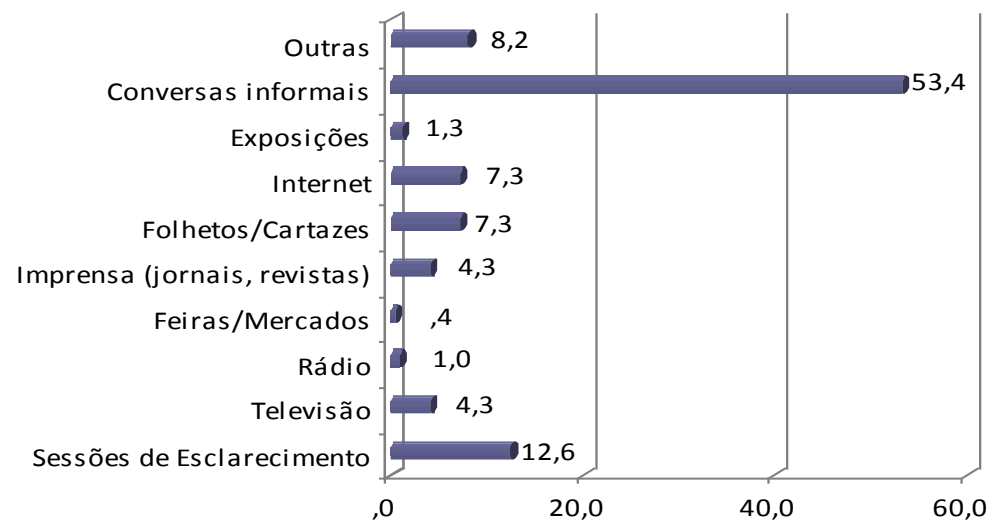

Fonte: Inquérito por Questionário das Novas Qualificações, 2011

\section{. Razões que conduziram ao processo de RVCC}

Procurámos conhecer, junto dos adultos certificados entre 2000 e 2005, as razões que os levaram a inscrever-se num CRVCC.

Figura 5 - Razões possíveis para frequentar o processo de RVCC

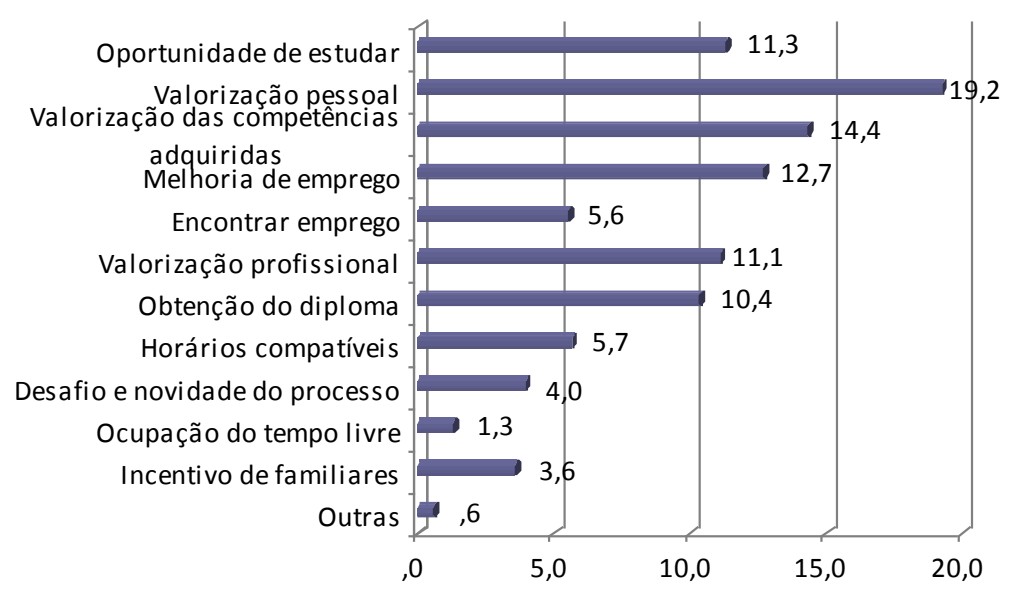

Fonte: Inquérito por Questionário das Novas Qualificações, 2011

Das razões apresentadas, aquela que reúne maiores escolhas é a Valorização Pessoal, com $19,2 \%$ do total de respostas expressas, o que evidencia que os adultos se 
mobilizaram para o processo por razões, maioritariamente, pessoais, realçando-se o reforço da auto-estima e a satisfação pessoal. Há ainda a destacar a expectativa de valorizar as competências adquiridas através da experiência da vida $(14,4 \%)$. Assim, podemos afirmar que quem procura mais o RVCC são os que anseiam por uma maior valorização pessoal. Esta inferência já havia sido referida em estudos anteriores (ESDIME, 2007; Rico \& Libório, 2009; Nico, 2009).

As razões associadas ao desenvolvimento pessoal $(33,6 \%)$ prevalecem sobre o desenvolvimento profissional $(29,4 \%)$ que surge num plano secundário.

\section{. Habilitações escolares antes do início do Processo de RVCC}

Quadro 2 - Adultos certificados, por habilitações escolares de acesso ao processo

\begin{tabular}{|c|c|c|}
\hline $\begin{array}{l}\text { Habilitações escolares } \\
\text { antes do ingresso no } \\
\text { processo de RVCC }\end{array}$ & $\begin{array}{l}\text { Frequência Absoluta } \\
\left(\text { (n. }^{\mathbf{0}}\right)\end{array}$ & $\begin{array}{c}\text { Frequência Relativa } \\
(\%)\end{array}$ \\
\hline $1^{\circ}$ ano de escolaridade & 5 & 0,6 \\
\hline $2^{\circ}$ ano de escolaridade & 15 & 1,9 \\
\hline $3^{\circ}$ ano de escolaridade & 8 & 1,0 \\
\hline $4^{\circ}$ ano de escolaridade & 128 & 16,3 \\
\hline $5^{\circ}$ ano de escolaridade & 22 & 2,8 \\
\hline $6^{\circ}$ ano de escolaridade & 325 & 41,4 \\
\hline $7^{\circ}$ ano de escolaridade & 54 & 6,9 \\
\hline $8^{\circ}$ ano de escolaridade & 87 & 11,1 \\
\hline $\begin{array}{l}9^{\circ} \text { ano de escolaridade } \\
\text { (incompleto) }\end{array}$ & 120 & 15,3 \\
\hline Sem resposta & 21 & 2,7 \\
\hline Totais & 785 & 100,0 \\
\hline
\end{tabular}

Fonte: Inquérito por Questionário das Novas Qualificações, 2011

Em termos de habilitações escolares de acesso dos adultos certificados entre $2001 \mathrm{e}$ 2003, verificamos o seguinte:

- $64 \%$ tem um nível de escolaridade inferior ao $6 .^{\circ}$ ano de escolaridade (incluído);

- $33,3 \%$ tem um nível de escolaridade superior ao $6 .^{\circ}$ ano de escolaridade;

. Níveis de certificação obtidos

Aproximadamente $90 \%$ dos adultos certificou o nível B3 (9. ${ }^{\circ}$ ano) e 4,2\% o nível B2 (6. ${ }^{\circ}$ ano), sendo residual o n. ${ }^{\circ}$ de certificações no nível B1 (Figura 6).

Figura 6 - Nível de certificação obtido

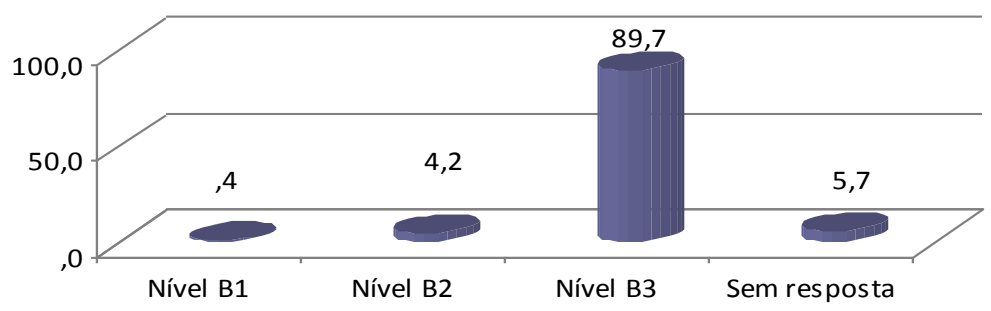

Fonte: Inquérito por Questionário das Novas Qualificações, 2011 


\section{. Impactos do Processo de RVCC}

No início do processo, os respondentes ao inquérito eram, maioritariamente, empregados. Procurámos saber de que forma é que a realização, com sucesso, do processo de RVCC induziu a eventuais alterações no percurso de vida profissional.

- Mudança de actividade profissional (adultos certificados/empregados)

Após o processo de RVCC, estando empregado, mudou de actividade profissional?

Observemos, de seguida, a Figura 7:

Figura 7 - Adultos certificados: mudança de actividade profissional

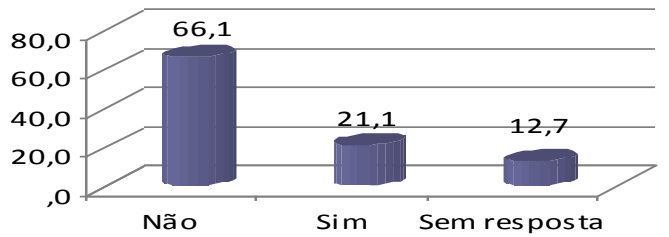

Fonte: Inquérito por Questionário das Novas Qualificações, 2011

Desde que se iniciou o processo e até ao momento de realização deste estudo, 66,1\% dos inquiridos mantém a actividade profissional (519), face aos $\mathbf{2 1 , 1 \%}$ que referem a mudança (166). Há 100 indivíduos que não responderam a esta questão, o que é um valor significativo.

No que respeita à influência do processo de RVCC nessa mudança profissional, observemos, agora, o Quadro 3:

Quadro 3 - Mudança profissional: importância atribuída ao processo de RVCC

\begin{tabular}{|l|c|c|}
\hline $\begin{array}{l}\text { O processo de RVCC } \\
\text { influenciou a mudança } \\
\text { profissional? }\end{array}$ & $\begin{array}{c}\text { Frequência Absoluta } \\
\left(\mathbf{n} \mathbf{0}^{\mathbf{0}}\right)\end{array}$ & $\begin{array}{c}\text { Frequência Relativa } \\
(\mathbf{\%})\end{array}$ \\
\hline Não influenciou & 40 & 23,3 \\
\hline 2 & 11 & 6,4 \\
\hline 3 & 33 & 19,2 \\
\hline 4 & 16 & 9,3 \\
\hline Influenciou muito & $\mathbf{7 2}$ & $\mathbf{4 1 , 8}$ \\
\hline Totais & 172 & 100,0 \\
\hline
\end{tabular}

Fonte: Inquérito por Questionário das Novas Qualificações, 2011

Em síntese, da leitura do quadro anterior, concluímos que, aproximadamente, 42\% dos respondentes que mudaram de profissão referiram que o processo de RVCC “influenciou muito” essa mudança.

- Encontrar um novo emprego (adultos certificados/desempregados)

Após o Processo de RVCC, estando desempregado encontrou emprego? 
A partir da análise do quadro seguinte, verificamos, assim, que, dos 132 indivíduos que estavam desempregados, mais de 50\% encontrou um emprego (67 indivíduos).

\section{Quadro 4 - Adultos desempregados que, após o processo de RVCC, encontraram um novo emprego}

\begin{tabular}{|l|c|c|}
\hline $\begin{array}{l}\text { Se desempregado, } \\
\text { encontrou emprego? }\end{array}$ & $\begin{array}{c}\text { Frequência Absoluta } \\
\left(\mathbf{n} \mathbf{.}^{\mathbf{o}}\right.\end{array}$ & $\begin{array}{c}\text { Frequência Relativa } \\
(\mathbf{\%})\end{array}$ \\
\hline Não & 65 & 49,2 \\
\hline Sim & $\mathbf{6 7}$ & $\mathbf{5 0 , 8}$ \\
\hline Totais & 132 & 100,0 \\
\hline \multicolumn{2}{|c|}{ Fonte: Inquérito por Questionário das Novas Qualificações, 2011 }
\end{tabular}

No que se refere ao período em que ocorreu essa mudança de situação face ao emprego, verificamos, pela análise da Figura 8 que, dos 67 adultos que encontraram emprego, $46(68,6 \%)$ conseguiram-no no período compreendido entre 1 a 3 ou mais anos.

\section{Figura 8 - Momento em que encontrou um novo emprego}

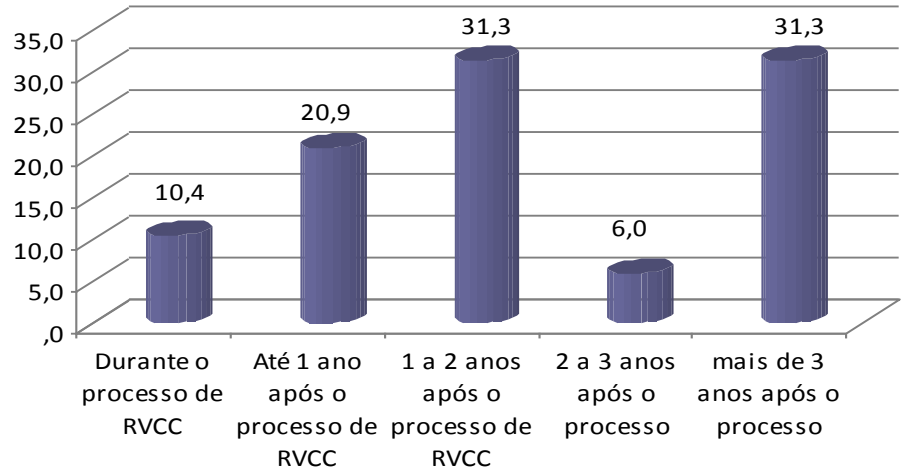

Fonte: Inquérito por Questionário das Novas Qualificações, 2011

Procurámos, ainda, conhecer de que forma, o processo de RVCC influenciou essa circunstância (indivíduo que estando desempregado após o processo de RVCC, encontrou um novo emprego).

Quadro 5 - Novo emprego: importância atribuída ao processo de RVCC

\begin{tabular}{|l|c|c|}
\hline $\begin{array}{l}\text { O processo de } \boldsymbol{R} \boldsymbol{V} \boldsymbol{C} C \\
\text { influenciou essa } \\
\text { mudança? }\end{array}$ & $\begin{array}{c}\text { Frequência Absoluta } \\
\left(\mathbf{n} \mathbf{0}^{\mathbf{0}}\right)\end{array}$ & $\begin{array}{c}\text { Frequência Relativa } \\
(\mathbf{\%})\end{array}$ \\
\hline Não influenciou & 16 & 23,9 \\
\hline 2 & 5 & 7,5 \\
\hline 3 & 15 & 22,4 \\
\hline 4 & 6 & 9,0 \\
\hline Influenciou muito & $\mathbf{2 1}$ & $\mathbf{3 1 , 2}$ \\
\hline Sem resposta & 4 & 6,0 \\
\hline Totais & 67 & 100,0 \\
\hline
\end{tabular}

Fonte: Inquérito por Questionário das Novas Qualificações, 2011 
Da leitura do Quadro 5, concluímos que, dos 67 indivíduos que encontraram um novo emprego, $31,3 \%$ refere que o processo de RVCC “influenciou muito" esse facto.

\section{A concluir...}

Como referimos, anteriormente, apresentaram-se, nesta comunicação, alguns resultados da investigação indicada, que continua a decorrer. Neste contexto, não será possível construir conclusões, atendendo à natureza parcelar da informação disponibilizada.

\section{Referências Bibliográficas}

ALONSO, Luísa et al (2001). Referencial de Competências-Chave - Educação e Formação de Adultos. Lisboa: ANEFA.

ANEFA (2002). Centros de Reconhecimento, Validação e Certificação de Competências: Roteiro Estruturante. Lisboa: ANEFA.

BENAVENTE, Ana et al (1996). A Literacia em Portugal. Resultados de uma pesquisa extensiva e monográfica. Lisboa: Fundação Calouste Gulbenkian.

CARNEIRO, Roberto (Coord.) (2010). Iniciativa Novas Oportunidades: resultados da Avaliação Externa 2009-2010. Lisboa: ANQ

ESDIME (2007). Estudo sobre o Impacto da Certificação de Competências na Vida das Pessoas: A Experiência da Esdime. Camarate: IEFP.

GOMES, Maria do Carmo \& SIMÕES, Francisca (2007). Carta de Qualidade dos Centros Novas Oportunidades. Lisboa: Agência Nacional para a Qualificação, I.P.

NICO, Lurdes Pratas (2009). Avaliação do(s) Impacto(s) do Processo de Reconhecimento, Validação e Certificação de Competências (RVCC), no Alentejo (período 2001-2005) [Tese apresentada à Universidade de Évora tendo em vista a obtenção do Grau de Doutor em Ciências da Educação]. Évora: Universidade de Évora (policopiada).

NICO, Lurdes Pratas (2011). A Escola da Vida: Reconhecimento e Validação dos Adquiridos Experienciais em Portugal. Fragmentos de uma Década (2000-2010). N.o 1. Colecção Educação, Território e Desenvolvimento Local. Mangualde: Edições Pedago.

RICO, Hugo \& LIBÓRIO, Tânia (2009). Impacte do Centro de RVCC da Fundação Alentejo na qualificação dos alentejanos. Évora: Fundação Alentejo

\section{Sítio de Internet consultado}

www.anqep.gov.pt

\section{Legislação referenciada}

Despacho n. ${ }^{\circ} 10534 / 97$, de 16 de Outubro 
Resolução do Conselho de Ministros n. ${ }^{\circ} 92 / 98$, de 14 de Julho

Decreto-Lei n. ${ }^{\circ} 387 / 99$, de 28 de Setembro

Portaria n. ${ }^{\circ} 1082-\mathrm{A} / 2001$, de 5 de Setembro

Portaria n. ${ }^{\circ} 475 / 2010$, de 8 de Julho

Portaria n. ${ }^{\circ} 370 / 2008$, de 21 de Maio 